\title{
Glass forming ability and soft-magnetic properties of Fe-based glassy alloys developed using high phosphorous pig Iron
}

\author{
Premkumar Murugaiyan ${ }^{\mathrm{a},}$, , Amitava Mitra ${ }^{\mathrm{a}}$, Rajat K. Roy ${ }^{\mathrm{a}}$, Pavan Bijalwan ${ }^{\mathrm{b}}$, \\ Monojit Dutta ${ }^{\mathrm{b}}$, Atanu Banerjee ${ }^{\mathrm{b}}$, Ashis K. Panda ${ }^{\mathrm{a}}$ \\ a NDE \& Magnetic Materials Group, AMP Division, CSIR-National Metallurgical Laboratory, Jamshedpur, Jharkhand, 831007, India \\ ${ }^{\mathrm{b}}$ Research and Development Division, Tata Steel limited, Jamshedpur, Jharkhand, 831007, India
}

\section{A R T I C L E I N F O}

\section{Article history:}

Received 1 September 2019

Received in revised form

26 November 2019

Accepted 1 December 2019

Available online 2 December 2019

\section{Keywords:}

Rapid solidification

Fe-based bulk metallic glass

Soft-magnetic alloy

Magnetization

Thermal analysis

\begin{abstract}
A B S T R A C T
Glass forming ability (GFA) and soft-magnetic behaviour of melt-spun $\mathrm{Fe}_{69} \mathrm{C}_{5.5} \mathrm{P}_{11.5} \mathrm{Mn}_{0.4} \mathrm{Si}_{2.3} \mathrm{Cr}_{1.8} \mathrm{Mo}_{1} \mathrm{~B}_{8.5}$ (alloy 2) and $\mathrm{Fe}_{68} \mathrm{C}_{9} \mathrm{P}_{12} \mathrm{Mn}_{1} \mathrm{Si}_{3} \mathrm{Nb}_{2} \mathrm{~B}_{5}$, (alloy 3) alloys prepared using high phosphorous pig iron (h-PI, $\mathrm{Fe}_{80} \mathrm{C}_{14} \mathrm{P}_{2.2} \mathrm{Mn}_{0.4} \mathrm{Si}_{3.4}$ ) has been studied. The glass formation, thermo-physical and soft-magnetic properties of the alloys were analyzed for different quenching rates by varying wheel speed as $23,26,33,39$ and $43 \mathrm{~m} / \mathrm{s}$. The simultaneous incorporation of alloying elements ( $\mathrm{Cr}, \mathrm{Mo}, \mathrm{Nb}$ ) and metalloids (C, B, P, Si) transforms h-PI to complete glassy alloy, even at low quenching rates. The melt quenching rate influences the thermal parameters and Curie temperature of glassy ribbons in an opposite way. Amongst all, FeCPMnSiCrMoB glassy alloy show superior combination of higher glass transition temperature of $788 \mathrm{~K}$, super cooled region of $34 \mathrm{~K}$, glass Curie temperature of $552 \mathrm{~K}$, coercivity less than $13 \mathrm{~A} / \mathrm{m}$ and maximum saturation magnetization of $1.1 \mathrm{~T}$. In addition, the annealing treatment at $758 \mathrm{~K}$ improves magnetic softness $(1.7 \mathrm{~A} / \mathrm{m})$ of the alloy by relaxation of quenched-in stresses. The comparison of developed glassy alloy with similar Fe-glassy alloys and SENNTIX type alloys show best combination of thermo-physical and magnetic properties. The glassy alloy prepared using blast furnace high phosphorous pig iron can be used for uniformly gapped soft-magnetic cores.
\end{abstract}

(c) 2019 Elsevier B.V. All rights reserved.

\section{Introduction}

The glassy soft-magnetic cores find extensive applications in electrical transmission and conditioning applications ranging from few $\mathrm{Hz}$ to $\mathrm{MHz}$ frequencies [1,2]. In recent times, glassy soft magnetic alloys in the form of uniformly gapped powder cores, draw attention due to their low coercivity, large magnetization, extended permeability range, DC bias characteristics and tunable resistivity $[3,4]$. Amongst different glassy systems, the Fe-based glassy softmagnetic alloys are preferred due to their low-cost raw materials, industrial adaptability, tailoring of magnetic and glass forming ability. Moreover, the Fe-based glassy soft magnetic core alloy requires a combination of good glass forming ability(GFA), optimal technical soft-magnetic properties, electrical resistivity and corrosion resistance, which would be applicable for preparing glassy alloy powders through atomization [2,5-7]. Similarly, a

\footnotetext{
* Corresponding author.

E-mail addresses: premkumar@nmlindia.org, premmtgce@gmail.com (P. Murugaiyan).
}

multicomponent FePBNbCr based glassy alloy under the tradename "SENNTIX" has been developed for high frequency electromagnetic applications [2,8]. A large number of Fe-based glassy alloys has been reported with high glass transition temperature $\left(T_{g} \geq 700 \mathrm{~K}\right)$ and extended super cooled region $\left(\Delta \mathrm{T}_{\mathrm{xg}}>15 \mathrm{~K}\right)$ combined with low coercivity $(\mathrm{Hc}<10 \mathrm{~A} / \mathrm{m})$ and high saturation magnetization $\left(\mathrm{M}_{\mathrm{S}}<100 \mathrm{emu} / \mathrm{g}\right)$ has been reported [9]. In general, the optimization of elemental percentage in multicomponent alloy design and optimization is a crucial approach for achieving desirable properties [10]. The GFA of Fe-based alloys is improved by the addition of d-block early transitional elements ( $\mathrm{Nb}, \mathrm{Zr}, \mathrm{Hf}, \mathrm{Sc}$ ) [11], metalloids like C, B, Si, P and semi-metals like Al, Ga [12,13]. Further, the thermal stability and soft-magnetic properties are improved by the replacement of base Fe with a minor additions of ferromagnetic Co and Ni elements [14]. Moreover, stable oxide forming elements like $\mathrm{Cr}, \mathrm{Mo}, \mathrm{Nb}, \mathrm{Al}, \mathrm{P}$ are incorporated for surface passivation properties [15,16]. The Fe glassy alloys are generally prepared using high purity raw materials and stringent refining conditions for achieving better GFA [17]. In particular, the melt impurities like oxides, inclusions adversely impact on GFA and magnetic properties. 
Recently, the researchers have attempted to utilize industrial cast iron and pig iron as the starting material for developing Fe-based glassy soft magnetic alloys [18,19]. The present work involves the utilization of high phosphorous pig iron (h-PI) material for developing glassy soft magnetic glassy alloys. The blast furnace h-PI material is abundant and considerable presence of $\mathrm{P}, \mathrm{C}, \mathrm{Si}$, encouraging for improved GFA and minimizing excessive alloy additions. Lastly, the structure, thermo-physical and DC magnetic properties are compared with the reported SENNTIX type and other pig iron based glassy alloys.

\section{Experimental techniques}

The master alloys with nominal composition, of $\mathrm{Fe}_{69} \mathrm{C}_{5.5} \mathrm{P}_{11.5} \mathrm{Mn}_{0.4} \mathrm{Si}_{2.3} \mathrm{Cr}_{1.8} \mathrm{Mo}_{1} \mathrm{~B}_{8.5}$ (alloy 2) and $\mathrm{Fe}_{68} \mathrm{C}_{9} \mathrm{P}_{12} \mathrm{Mn}_{1-}$ $\mathrm{Si}_{3} \mathrm{Nb}_{2} \mathrm{~B}_{5}$, (alloy 3 ) were prepared in arc-melting furnace, using high phosphorous pig Iron (h-PI, of $\mathrm{Fe}_{80} \mathrm{C}_{14} \mathrm{P}_{2.2} \mathrm{Mn}_{0.4} \mathrm{Si}_{3.4}$ ) and premelted ferro-alloys of $\mathrm{Fe}-\mathrm{Cr}$, $\mathrm{Fe}-\mathrm{Nb}, \mathrm{Fe}-\mathrm{P}, \mathrm{Fe}-\mathrm{C}, \mathrm{Fe}-\mathrm{B}$ and $\mathrm{Fe}-\mathrm{Mo}$. The alloy re-melting for homogenization and subsequent ingot casting have been carried out by a vacuum induction furnace under inert atmosphere. Furthermore, the molten alloy ingots were rapidly quenched on $\mathrm{Cu}-\mathrm{Be}$ wheel at different wheel speed of 23 , $26,33,39$ and $43 \mathrm{~m} / \mathrm{s}$ for preparing continuous melt-spun ribbons. Except h-PI alloy, ribbons are continuous of width $5 \mathrm{~mm}$ showing good metallic lustre. The structural properties were studied on the shiny (air) side of the ribbon by X-Ray Diffractometry (XRD, Bruker D8 Discover) using $\mathrm{Cu}-\mathrm{K} \alpha$ radiation source. The thermo-physical properties were obtained using Differential Scanning Calorimetry (DSC, PerkinElmer) at a heating rate of $0.67 \mathrm{~K} / \mathrm{s}$. The annealing treatment of the melt-spun ribbons were carried out using Infrared furnace with a holding time of $900 \mathrm{~s}$ under continuous flow of $\mathrm{Ar}$ gas. The magnetic coercivity $\left(\mathrm{H}_{\mathrm{c}}\right)$ were measured by in-house developed $\mathrm{B}-\mathrm{H}$ loop tracer based on open-flux configuration. A ribbon coupons of $8-10 \mathrm{~cm}$ were considered for the annealing treatment and $\mathrm{B}-\mathrm{H}$ loop measurement. The saturation magnetization $\left(\mathrm{M}_{\mathrm{S}}\right)$ curves were obtained using Vibrating Sample Magnetometer (VSM, Quantum Design Inc.) with a maximum applied field of $1.2 \mathrm{~T}$. The material weight and density were obtained from precision density analyzer (Mettler Toledo, XS204).

\section{Results and discussion}

\subsection{As-quenched ribbons}

The average thickness $(t)$ of melt spun ribbon i.e. cross sectional area, decreases with increasing melt-spinning wheel speed (Table 1), relating to the molten alloy quenching rate [20,21]. Fig. 1

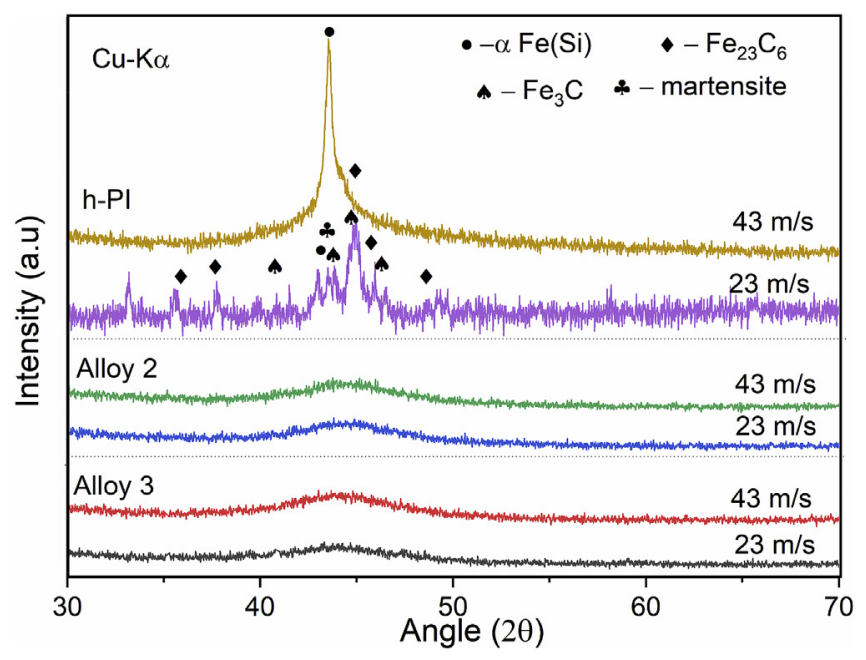

Fig. 1. XRD patterns of as-quenched alloy ribbons obtained from low and high wheel speed.

shows the XRD patterns of thicker and thinner alloy ribbons obtained at low $(23 \mathrm{~m} / \mathrm{s})$ and high $(43 \mathrm{~m} / \mathrm{s})$ wheel speed, respectively. The thick ribbon of h-PI alloy exhibits the presence of multiple peaks of $\alpha-\mathrm{Fe}(\mathrm{Si})$, martensite, $\mathrm{Fe}_{3} \mathrm{C}(\mathrm{P})$ and $\mathrm{Fe}_{23} \mathrm{C}_{6}$, indicating the formation of multi-phase crystalline structure due to poor quenching rate. In contrast, thin h-PI ribbon (wheel speed: $43 \mathrm{~m} / \mathrm{s}$ ) exhibits composite structure comprising amorphous hump alongwith single $\alpha-\mathrm{Fe}(\mathrm{Si})$ crystal peak. Conversely, the entire Alloy $2 \& 3$ ribbons show broad hump region $\left(2 \theta=40-50^{\circ}\right)$, without any crystal peak indicating the formation of complete amorphous structure. The sharp structural difference indicates low critical cooling rate and better glass forming ability (GFA) for Alloy 2 and 3 . Moreover, the lack of complete amorphization for h-PI ribbons occurs, even at high wheel speed signifying the presence of insufficient metalloid content and/or the intervention of crystallization through melt impurities [22]. The GFA enhancement of multicomponent alloys is attributed to the large presence of metalloids (B, P, Si, C) and alloying elements ( $\mathrm{Cr}, \mathrm{Mo}, \mathrm{Nb}$ ) [9]. The significant atomic mismatch and negative enthalpy of mixing (-ve $\Delta \mathrm{H}_{\text {mix }}$ ) between Fe and additive elements contributes to better chemical, topological cluster packing in the liquid melt and congeal the glassy structure [11]. Additionally, numerous empirical thermodynamic and topological model parameters like $\mathrm{T}_{\mathrm{rg}}, \mathrm{P}_{\mathrm{hss}}$, e/u ratio evidences improvement of GFA of Fe-based glassy alloys through multicomponent alloying [13,23-25].

Table 1

The physical, structural, thermal and soft-magnetic properties of as-quenched alloy ribbons.

\begin{tabular}{|c|c|c|c|c|c|c|c|c|c|}
\hline Alloy & Wheel speed $(\mathrm{m} / \mathrm{s})$ & Avg. Ribbon thickness $\mathrm{t}(\mu \mathrm{m})$ & structure & $\mathrm{T}_{\mathrm{c}}$ & $\mathrm{T}_{\mathrm{g}}(\mathrm{K})$ & $\Delta \mathrm{T}_{\mathrm{xg}}(\mathrm{K})$ & $\mathrm{T}_{\mathrm{x} 1}(\mathrm{~K})$ & $\mathrm{Hc}(\mathrm{A} / \mathrm{m})$ & $\mathrm{M}_{\mathrm{s}}(\mathrm{T})$ \\
\hline \multirow[t]{5}{*}{ h-PI } & 22 & 80 & crystalline & & & & & $63 \pm 3.6$ & 1.3 \\
\hline & 26 & 75 & crystalline & & & & & $71 \pm 2.0$ & 1.3 \\
\hline & 33 & 48 & Amo + cryst & & & & 795 & $44 \pm 1.2$ & 1.4 \\
\hline & 39 & 32 & Amo + cryst & & & & 844 & $42 \pm 0.8$ & 1.4 \\
\hline & 43 & 29 & Amo + Cryst & & & & 849 & $41 \pm 0.9$ & 1.4 \\
\hline \multirow[t]{5}{*}{ Alloy 2} & 22 & 65 & glass & 552 & 782 & 34 & 816 & $13 \pm 0.4$ & 1.1 \\
\hline & 26 & 55 & glass & 550 & 781 & 32 & 813 & $6 \pm 0.2$ & 1.0 \\
\hline & 33 & 51 & glass & 551 & 780 & 31 & 811 & $7 \pm 0.3$ & 1.1 \\
\hline & 39 & 34 & glass & 552 & 786 & 27 & 813 & $9 \pm 0.2$ & 1.0 \\
\hline & 43 & 31 & glass & 554 & 788 & 31 & 819 & $12 \pm 0.1$ & 1.1 \\
\hline \multirow[t]{5}{*}{ Alloy 3} & 22 & 58 & glass & 586 & 725 & 33 & 763 & $5 \pm 0.4$ & 0.9 \\
\hline & 26 & 45 & glass & 586 & 728 & 33 & 761 & $15 \pm 0.5$ & 0.9 \\
\hline & 33 & 38 & glass & 584 & 729 & 37 & 766 & $10 \pm 0.4$ & 0.9 \\
\hline & 39 & 35 & glass & 585 & 730 & 36 & 766 & $5 \pm 0.2$ & 0.9 \\
\hline & 43 & 33 & glass & 584 & 735 & 32 & 767 & $9 \pm 0.2$ & 0.9 \\
\hline
\end{tabular}



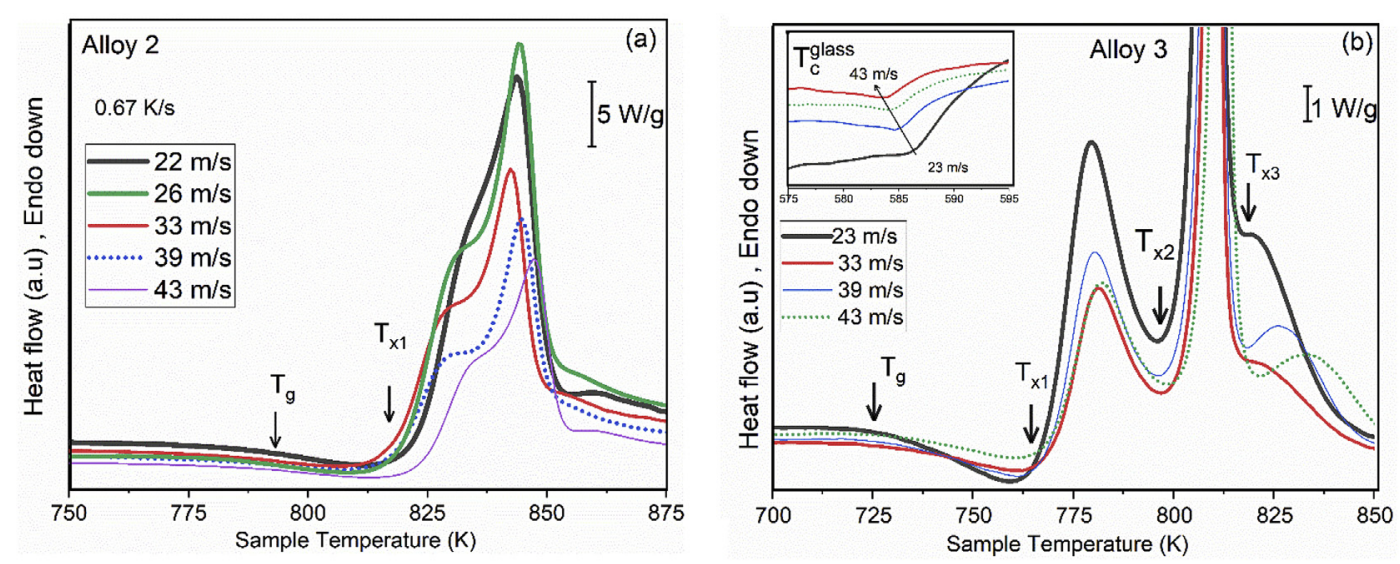

Fig. 2. DSC thermogram of as-quenched ribbons obtained at various wheel speeds for a) Alloy 2 and b) Alloy 3.

\subsection{Thermal properties}

The characteristic thermal parameters like glass transition temperature $\left(T_{g}\right)$, the onset of crystallization $\left(T_{x}\right)$, supercooled region $\left(\Delta \mathrm{T}_{\mathrm{xg}}\right)$, amorphous Curie temperature $\left(\mathrm{T}_{\mathrm{c}}\right)$ are discussed in Table 1. The DSC thermograms of all alloys demonstrate the influence of quenching rate on thermal properties. The $T_{x 1}$ temperature of h-PI ribbons replicates the quenching rate through disappearing $T_{x 1}$, for thicker ribbons and increasing $T_{x 1}$ of 795,844 and $849 \mathrm{~K}$ with a wheel speed of 33, 39 and $43 \mathrm{~m} / \mathrm{s}$, respectively, for thinner ribbons (Table 1). The drastic change of $T_{x 1}$ from $33 \mathrm{~m} / \mathrm{s}$ is attributed to the difference in residual amorphous matrix composition. On the other hand, the DSC thermogram of both Alloy 2 and 3 show the occurrence of $T_{g}, \Delta T_{x g}$ and $T_{x}$ region, justifying glassy nature of the alloys (Fig. 2). The DSC results substantiate the XRD result of enhanced GFA for multi-component alloys. Amongst the glassy alloys, the alloy 2 possess higher $\mathrm{T}_{\mathrm{g}}$ of $780-788 \mathrm{~K}$ compared to alloy 3 ( $\mathrm{T}_{\mathrm{g}} \sim 725-735 \mathrm{~K}$ ) attributing better GFA and as-quenched structure stabilization for the former alloy. Except for Curie temperature $\left(\mathrm{T}_{\mathrm{C}}\right)$, other thermal parameters show a slight shifting towards higher temperature with increasing quenching rate (23-43 m/s) (Table .1). However, the increase in $T_{g}$ and $\Delta \mathrm{T}$ is minimal. It is noteworthy that glassy alloys depict a decreasing area under endothermic supercooled region from thicker to thinner ribbons (Fig. 2 a\&b). The minimal area attributes to the difference in short-range ordering of clusters with increasing quenching rate [26]. Also, the shifting of $T_{x}$ towards higher temperature indicates the varied level of glass structure stabilization through free volume generation and relaxation process [27]. Further, the glassy alloy $2 \& 3$ exhibit double (Fig. 2a) and triple (Fig. 2b) crystallization event during the de-vitrification process. In case of alloy 2, the first and second exothermic peaks overlap for thicker ribbons and tends to separate for thinner ribbons. Similarly, the distinct peak separation with higher quenching rate is observed for alloy 3 . The crystallization being diffusion controlled process, the solute rejection takes place during primary crystallization, enriches solute atom in the residual glassy matrix [28]. Subsequent crystallization $\left(\mathrm{T}_{\mathrm{x} 2} \& \mathrm{~T}_{\mathrm{x} 3}\right)$ occurs from the solute enriched intergranular residual matrix (Fig. 2). The incidence of double and triple crystallization event in alloys 2 and 3, can be attributed to the difference in solid solubility of d-block transition alloying elements. Particularly, alloy 2 consisting Mo and $\mathrm{Cr}$ has better solid solubility in $\alpha$-Fe, compared to $\mathrm{Nb}$ in alloy 3 and allows for less solute rejection process after primary crystallization [29].

\subsection{Soft-magnetic properties}

The magnetic coercivity $\left(\mathrm{H}_{\mathrm{c}}\right)$ of as-quenched alloys exhibit clear demarcation between partially amorphous h-PI alloy and glassy multicomponent alloys (Table 1). A drop in $\mathrm{H}_{\mathrm{c}}$ from 63 to $71 \mathrm{~A} / \mathrm{m}$ for thicker h-PI ribbons $(23,26 \mathrm{~m} / \mathrm{s})$ to $(\sim 41-44 \mathrm{~A} / \mathrm{m})$ for thinner ribbons are observed. The reduction in $\mathrm{H}_{\mathrm{c}}$ is due to the presence of non-magnetic crystalline phases. The complex crystal structure of $\mathrm{Fe}_{3} \mathrm{C}(\mathrm{P})$ possess large magneto-crystalline anisotropy $\left(\mathrm{K}_{1}\right)$ and negatively affects domain wall movement through the pinning mechanism [30]. In the case of thinner h-PI ribbons, the ferromagnetic $\alpha$-Fe $(\mathrm{Si})$ phase dispersed in partially amorphous structure lowers $\mathrm{H}_{c}$ by the absence of complex crystal phases. Nevertheless, still higher $\mathrm{H}_{\mathrm{c}}$ is due to the strong grain size dependency of $\mathrm{H}_{\mathrm{c}}$ and volume fraction of crystallite $\alpha$-Fe ( $\mathrm{Si}$ ) phase in the amorphous matrix [31]. Conversely, the glassy alloy $2 \& 3$ ribbons show low $\mathrm{H}_{\mathrm{c}}(<15 \mathrm{~A} / \mathrm{m})$ for all wheel speeds (Table 1$)$. The low $\mathrm{H}_{\mathrm{C}}$ of glassy alloys is due to the vanishing magneto-crystalline anisotropy $\left(\mathrm{K}_{1}\right)$ by the absence of long-range crystal periodicity. Therefore, the $\mathrm{H}_{\mathrm{c}}$ of as-quenched ribbons are governed by magneto-elastic anisotropy $\left(\mathrm{K}_{\mathrm{e}}\right)$. The variation of $\mathrm{H}_{\mathrm{c}}$ amongst the ribbons of different wheel speeds is due to the presence of large

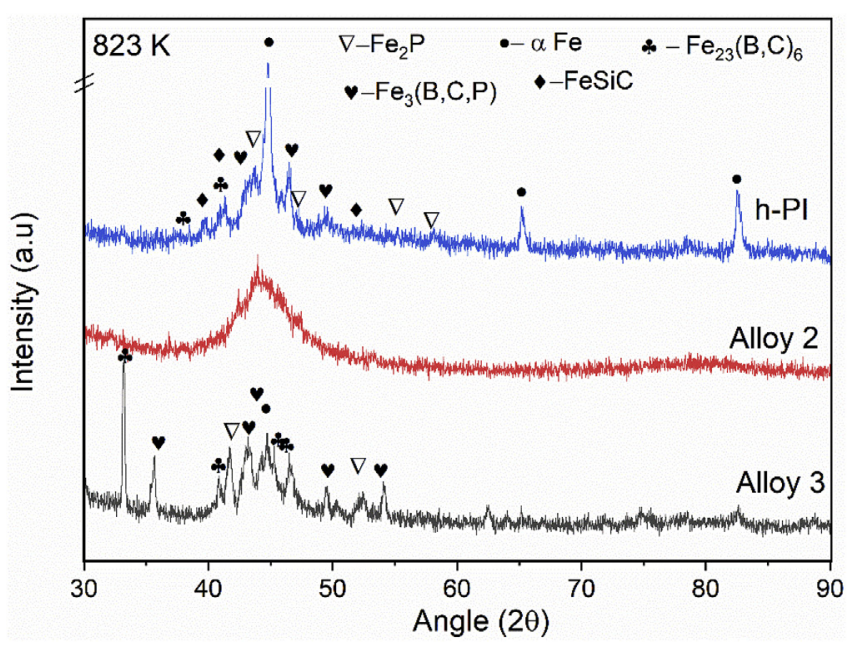

Fig. 3. XRD patterns of ribbons annealed at $823 \mathrm{~K}$. 

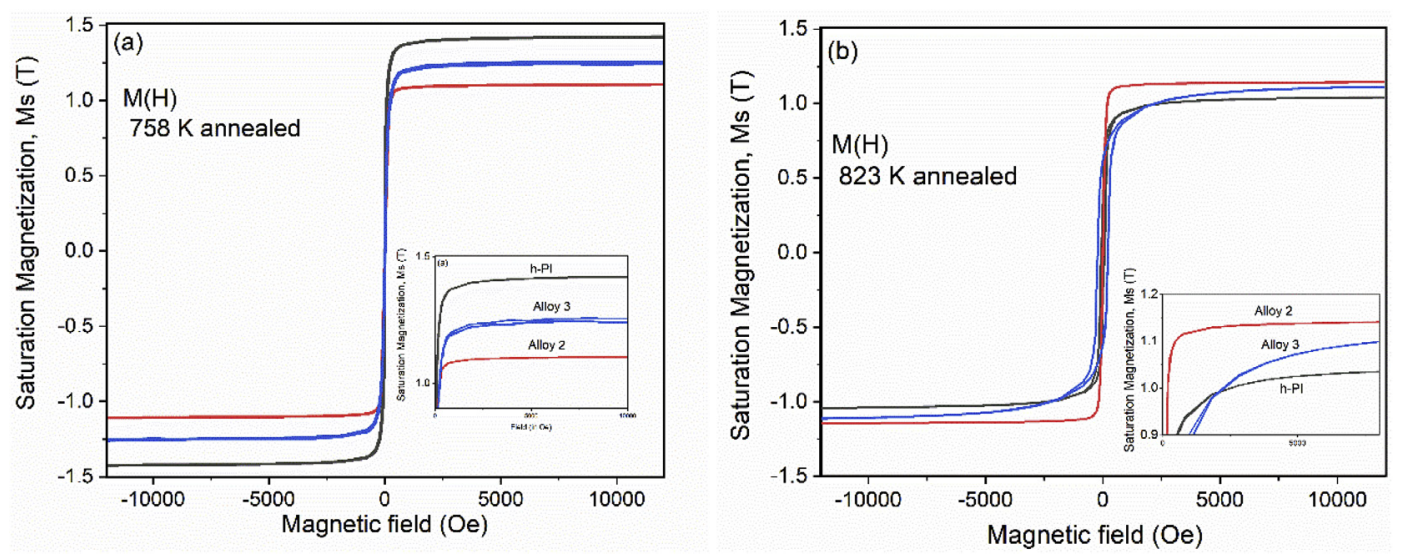

Fig. 4. The room temperature saturation magnetization $\left(\mathrm{M}_{\mathrm{s}}\right)$ curves of ribbons annealed at a) $758 \mathrm{~K}$ and b) $823 \mathrm{~K}$.

quenched-in stresses across the ribbon cross-section. The locked-in stresses in association with magnetostriction property influence the $\mathrm{K}_{\mathrm{e}}$, thereby the magnetic domain wall movement [32]. Furthermore, the low $\mathrm{H}_{\mathrm{c}}$, for intermediate wheel speeds in alloy 2 and the inverse behaviour for alloy 3 can be related to the surface defects and self-annealing nature of thicker ribbons [33].

The saturation magnetization $\left(\mathrm{M}_{\mathrm{s}}\right)$ of as-quenched alloy ribbons are listed in Table 1 . The h-PI exhibit maximum $\mathrm{M}_{\mathrm{s}}$ due to large Fecontent and composite structure of dispersed ferromagnetic $\alpha$ $\mathrm{Fe}(\mathrm{Si})$ crystallites in amorphous matrix. On the other hand, the alloy 2 and 3 exhibit lower $M_{s}$ and the latter is being the least due to ferromagnetic dilution.

\subsection{Annealing treatment}

The soft-magnetic properties of melt-spun alloys can be further improved by suitable heat-treatment, causing internal stress relaxation or by the controlled precipitation of ferromagnetic nanocrystallites [34]. To understand the annealing effect on softmagnetic properties, the melt-spun ribbons of $33 \mathrm{~m} / \mathrm{s}$ wheel speed are subjected to 758 and $823 \mathrm{~K}$ for $900 \mathrm{~s}$ respectively. The annealing temperature of 758 and $823 \mathrm{~K}$ is chosen below and above $\mathrm{T}_{\mathrm{x} 1}$ temperatures, representing the stress-relief and crystallization region. Fig. 3 depicts the XRD pattern of ribbons annealed at $823 \mathrm{~K}$. Both h-PI and alloy 3 ribbon exhibit the presence of multi-phase crystallization in amorphous matrix. Whereas, the alloy 2 show amorphous hump with minor crystal peak indicating predominantly glassy matrix. The structural difference evidences the enhanced thermal stability and glassy structure stabilization of alloy 2 during de-vitrification.

The h-PI, alloy 2 and alloy 3 ribbons annealed at $758 \mathrm{~K}$ show magnetic coercivity $\left(\mathrm{H}_{\mathrm{c}}\right)$ of $398,1.7$ and $264 \mathrm{~A} / \mathrm{m}$, respectively. For still higher annealing temperature of $823 \mathrm{~K}$, the $\mathrm{H}_{\mathrm{c}}$ deteriorates drastically to $985 \mathrm{~A} / \mathrm{m}$ and $540 \mathrm{~A} / \mathrm{m}$ for h-PI and alloy 3. On the other side, the alloy 2 annealed ribbon shows a slight increase in $\mathrm{H}_{C}$ to $5.5 \mathrm{~A} / \mathrm{m}$. The $\mathrm{H}_{\mathrm{c}}$ behaviour complements the XRD result of annealed ribbons. The annealed h-PI and alloy 3 ribbons exhibit poor thermal stability by precipitating multiple non-magnetic crystal phases. These non-magnetic crystallites negatively affect the soft-magnetic properties $\left(\mathrm{H}_{\mathrm{c}}\right)$ through domain wall pinning [35]. Whereas, alloy 2 having glassy matrix even at $823 \mathrm{~K}$, retains soft-magnetic properties due to the absence of large crystal anisotropy $\left(\mathrm{K}_{1}\right)$ and reduction of magneto-elastic anisotropy $\left(\mathrm{K}_{\mathrm{e}}\right)$ by internal quenched-in stress relaxation. The saturation magnetization $\left(\mathrm{M}_{\mathrm{S}}\right)$ decreases in the order of h-PI, alloy 3 and alloy 2 for $758 \mathrm{~K}$ annealed ribbons and reverses for $823 \mathrm{~K}$ (Fig. 4). The reversal of $\mathrm{M}_{s}$ for higher annealing temperatures is due to precipitation of nonmagnetic crystalline phases as observed in Fig. 3. Besides, the $M_{s}$ curves of $823 \mathrm{~K}$ annealed sample explicitly show high $\mathrm{M}_{\mathrm{s}}$, low $\mathrm{H}_{\mathrm{c}}$ rectangular loop for predominantly glassy Alloy 2 compared to low $\mathrm{M}_{\mathrm{S}}$, circular loop for crystallized h-PI sample (Fig. 4b). The annealing study explains the favourable combination of ultra-soft magnetic properties and better thermal stability for alloy 2 annealed at $758 \mathrm{~K}$. Moreover, the soft-magnetic deterioration occurs for all alloys with crystallite precipitation during the devitrification process.

Table 2 compares the thermal and soft magnetic properties of alloy 2 with reported literatures including SENNTIX type alloys. The data clearly explains the favourable combination of glass forming ability, thermal stability and soft magnetic properties compared to other alloys.

\section{Conclusion}

The study investigates the development of Fe-based glassy alloys using blast furnace high phosphorous pig iron. The quenching rate modulation by wheel speed proves to be an effective way of understanding the GFA of developed alloys. The rapidly quenched h-PI shows weak glass-forming ability and forms composite microstructure. The as-quenched alloy 2 \& 3 ribbons show glassy characteristics and exhibit better soft magnetic properties. The glassy alloy 2 possess excellent thermal stability coupled with low

Table 2

Comparison of physical, thermal and magnetic properties of select Fe-based glassy alloys and prepared alloy.

\begin{tabular}{|c|c|c|c|c|c|c|c|c|}
\hline Alloy composition & Structure & $\mathrm{T}_{\mathrm{c}}$ & $\mathrm{T}_{\mathrm{g}}(\mathrm{K})$ & $\Delta \mathrm{T}(\mathrm{K})$ & $\mathrm{T}_{\mathrm{x} 1}(\mathrm{~K})$ & $\mathrm{Hc}(\mathrm{A} / \mathrm{m})$ & Ms (T) & Ref \\
\hline $\mathrm{Fe}_{71.2} \mathrm{C}_{7} \mathrm{Si}_{3.3} \mathrm{~B}_{5.5} \mathrm{P}_{8.7} \mathrm{Cr}_{2.3} \mathrm{Al}_{2}$ & Glass & 578 & 788 & 21 & 809 & 12.6 & 0.9 & [19] \\
\hline $\mathrm{Fe}_{68.2} \mathrm{C}_{7} \mathrm{Si}_{3.3} \mathrm{~B}_{5.5} \mathrm{P}_{8.7} \mathrm{Cr}_{2.3} \mathrm{Al}_{2} \mathrm{Co}_{3}$ & Glass & 590 & 789 & 19 & 808 & 9.3 & 1.03 & [19] \\
\hline $\mathrm{Fe}_{77} \mathrm{P}_{9} \mathrm{~B}_{11} \mathrm{Nb}_{2} \mathrm{Cr}_{1}$ (SENNTIX) & Glass & 556 & 767 & 36 & 795 & 2.5 & 1.3 & [2] \\
\hline $\mathrm{Fe}_{77} \mathrm{P}_{11} \mathrm{~B}_{9} \mathrm{Nb}_{2} \mathrm{Cr}_{1}$ (SENNTIX) & Glass & 549 & 754 & 29 & 783 & 3.1 & 1.3 & [2] \\
\hline $\mathrm{Fe}_{84} \mathrm{Cr}_{2} \mathrm{~B}_{8} \mathrm{Si}_{2} \mathrm{P}_{4}$ & Amorphous & - & - & - & 689 & 9.1 & 1.5 & [3] \\
\hline $\mathrm{Fe}_{69} \mathrm{C}_{5.5} \mathrm{P}_{11.5} \mathrm{Mn}_{0.4} \mathrm{Si}_{2.3} \mathrm{Cr}_{1.8} \mathrm{Mo}_{1} \mathrm{~B}_{8.5}$ & Glass & 552 & 782 & 34 & 816 & $1.7^{\mathrm{a}}$ & $1.05^{\mathrm{a}}$ & This work \\
\hline
\end{tabular}

a $758 \mathrm{~K}$ annealed. 
$\mathrm{H}_{\mathrm{c}}$ of $1.7 \mathrm{~A} / \mathrm{m}$ and $\mathrm{Ms}$ of $1.05 \mathrm{~T}$ on annealing at $758 \mathrm{~K}$. The study suggests an alternative raw material for glassy soft magnetic alloy preparation and its potential applicability in electromagnetic powder cores.

\section{Author contribution statement}

Premkumar Murugaiyan: Conceptualization, Methodology,

Writing - Original Draft

Amitava Mitra: Project administration, Funding Acquisition

Rajat K Roy: Data Curation, Writing - Review \& Editing.

Pavan Bijalwan: Investigation.

Monojit Dutta: Project administration, Funding Acquisition

Atanu Banerjee: Methodology, Visualization, Supervision.

Ashis K. Panda: Resources, Investigation

\section{Declaration of competing interest}

The authors declare that they have no known competing financial interests or personal relationships that could have appeared to influence the work reported in this paper.

\section{Acknowledgement}

The research work is based on collaborative project (CLP-0188) jointly supported by CSIR-National Metallurgical Laboratory and Tata Steel Ltd, Jamshedpur.

\section{Appendix A. Supplementary data}

Supplementary data to this article can be found online at https://doi.org/10.1016/j.jallcom.2019.153255.

\section{References}

[1] T. Kauder, K. Hameyer, Performance factor comparison of nanocrystalline, amorphous and crystalline soft magnetic materials for medium frequency applications, in: 2017 IEEE Int. Magn. Conf. INTERMAG, 2017, https://doi.org 10.1109/INTMAG.2017.8007889, 9464 (2017) 2015-2018.

[2] H. Matsumoto, A. Urata, Y. Yamada, A. Inoue, FePBNbCr soft magnetic glassy alloys "SENNTIX" with low loss characteristics for commercial inductor cores, Mater. Sci. Forum 654-656 (2010) 1098-1101, https://doi.org/10.4028/ www.scientific.net/msf.654-656.1098.

[3] Y. Han, F.L. Kong, F.F. Han, A. Inoue, S.L. Zhu, E. Shalaan, F. Al-Marzouki, New Fe-based soft magnetic amorphous alloys with high saturation magnetization and good corrosion resistance for dust core application, Intermetallics 76 (2016) 18-25, https://doi.org/10.1016/j.intermet.2016.05.011.

[4] Z. Li, Y. Dong, S. Pauly, C. Chang, R. Wei, F. Li, X.M. Wang, Enhanced soft magnetic properties of Fe-based amorphous powder cores by longitude magnetic field annealing, J. Alloy. Comp. 706 (2017) 1-6, https://doi.org/ 10.1016/j.jallcom.2017.02.202.

[5] T. Li, Y. Dong, L. Liu, M. Liu, X. Shi, X. Dong, O. Rong, Novel Fe-based nanocrystalline powder cores with high performance prepared by using industrial materials, Intermetallics 102 (2018) 101-105, https://doi.org/10.1016/ j.intermet.2018.09.001.

[6] J. Guo, Y. Dong, Q. Man, Q. Li, C. Chang, X.M. Wang, R.W. Li, Fabrication of FeSiBPNb amorphous powder cores with high DC-bias and excellent soft magnetic properties, J. Magn. Magn. Mater. 401 (2016) 432-435, https:// doi.org/10.1016/j.jmmm.2015.10.069.

[7] Y. Liu, Y. Yi, W. Shao, Y. Shao, Microstructure and magnetic properties of soft magnetic powder cores of amorphous and nanocrystalline alloys, J. Magn Magn. Mater. 330 (2013) 119-133, https://doi.org/10.1016 j.jmmm.2012.10.043.

[8] SENNTIX-type amorphous alloys with high Bs and improved corrosion resistance, J. Alloy. Comp. 707 (2017) 195-198, https://doi.org/10.1016/ j.jallcom.2016.10.083.

[9] H.X. Li, Z.C. Lu, S.L. Wang, Y. Wu, Z.P. Lu, Fe-based bulk metallic glasses: glass formation, fabrication, properties and applications, Prog. Mater. Sci. 103 (2019) 235-318, https://doi.org/10.1016/j.pmatsci.2019.01.003.

[10] J. Xu, C. Shang, W. Ge, H. Jia, P.K. Liaw, Y. Wang, Effects of elemental addition on the microstructure, thermal stability, and magnetic properties of the mechanically alloyed FeSiBAINi high entropy alloys, Adv. Powder Technol. (2015) 1-9, https://doi.org/10.1016/j.apt.2016.04.037.

[11] A. Takeuchi, A. Inoue, Metallic glasses by atomic size difference, heat of mixing and period of constituent elements and its application to characterization of the main alloying element, Mater. Trans. 46 (2005) 2817-2829, https:// doi.org/10.2320/matertrans.46.2817.

[12] T. Hibino, T. Bitoh, Ternary Fe-B-C and quaternary Fe-B-C-Si amorphous alloys with glass transition and high magnetization, J. Alloy. Comp. 707 (2017) 82-86, https://doi.org/10.1016/j.jallcom.2016.12.060.

[13] C. Suryanarayana, A. Inoue, Iron-based bulk metallic glasses, Int. Mater. Rev. 58 (2013) 131-166, https://doi.org/10.1179/1743280412Y.0000000007.

[14] K.E. Knipling, M. Daniil, M.A. Willard, Nanocrystalline Fe882xCoxNixZr7B4Cu1alloys: soft magnets for vehicle electrification technologies (invited), J. Appl. Phys. 117 (2015), https://doi.org/10.1063/1.4914118, $0-5$.

[15] J. Li, L. Yang, H. Ma, K. Jiang, C. Chang, J.Q. Wang, Z. Song, X. Wang, R.W. Li, Improved corrosion resistance of novel Fe-based amorphous alloys, Mater. Des. 95 (2016) 225-230, https://doi.org/10.1016/j.matdes.2016.01.100.

[16] H.X. Li, Z.C. Lu, S.L. Wang, Y. Wu, Z.P. Lu, Fe-based bulk metallic glasses: glass formation, fabrication, properties and applications, Prog. Mater. Sci. 103 (2019) 235-318, https://doi.org/10.1016/j.pmatsci.2019.01.003.

[17] J.F. Li, X. Liu, S.F. Zhao, H.Y. Ding, K.F. Yao, Fe-based bulk amorphous alloys with iron contents as high as 82 at\%, J. Magn. Magn. Mater. 386 (2015) 107-110, https://doi.org/10.1016/j.jmmm.2015.03.070.

[18] A. Inoue, X.M. Wang, Bulk amorphous FC20 (Fe-C-Si) alloys with small amounts of $\mathrm{B}$ and their crystallized structure and mechanical properties, Acta Mater. 48 (2000) 1383-1395, https://doi.org/10.1016/S1359-6454(99)003948.

[19] H.X. Li, S.L. Wang, S. Yi, Z.B. Jiao, Y. Wu, Z.P. Lu, Glass formation and magnetic properties of $\mathrm{Fe}-\mathrm{C}-\mathrm{Si}-\mathrm{B}-\mathrm{P}-(\mathrm{Cr}-\mathrm{Al}-\mathrm{Co})$ bulk metallic glasses fabricated using industrial raw materials, J. Magn. Magn. Mater. 321 (2009) 2833-2837, https://doi.org/10.1016/j.jmmm.2009.04.021.

[20] D. Singh, D. Singh, R.K. Mandal, O.N. Srivastava, R.S. Tiwari, Effect of quenching rate on the microstructure and mechanical behavior of Ce $75 \mathrm{Al} 21 \mathrm{Ga} 4$ glassy alloy, Mater. Char. 134 (2017) 18-24, https://doi.org/10.1016/ j.matchar.2017.09.037.

[21] B. Jiang, J. Wang, L. Xu, C. Qian, T. Liu, J. Dai, X. Hou, Tunable mechanical properties of Ti-Zr-Ni-Cr-V amorphous ribbons via different melt spinning speeds during rapid solidification process, Materials 11 (2018), https:// doi.org/10.3390/ma11060947.

[22] H. Zheng, L. Hu, X. Zhao, C. Wang, Q. Sun, T. Wang, X. Hui, Y. Yue, X. Bian, Poor glass-forming ability of Fe-based alloys: its origin in high-temperature melt dynamics, J. Non-Cryst. Solids 471 (2017) 120-127, https://doi.org/10.1016/ j.jnoncrysol.2017.05.026.

[23] P. Murugaiyan, A. Mitra, A.K. Patro, R.K. Roy, M. Churyukanova, S. Kaloshkin, E. Shuvaeva, A.K. Panda, Role of P on amorphization, microstructure, thermophysical and soft magnetic properties of Fe-rich $\mathrm{FeB}(\mathrm{P}) \mathrm{SiNbCu}$ melt-spun alloys, J. Magn. Magn. Mater. 492 (2019), https://doi.org/10.1016/ j.jmmm.2019.165723.

[24] N. Mahata, A. Banerjee, P.K. Rai, P. Bijalwan, A.S. Pathak, S. Kundu, M. Dutta, K. Mondal, Glassy blast furnace pig iron and design of other glassy compositions using thermodynamic calculations, J. Non-Cryst. Solids 484 (2018) 95-104, https://doi.org/10.1016/j.jnoncrysol.2018.01.029.4. ISSN 0022-3093.

[25] J. Du, C. Dong, R. Melnik, Y. Kawazoe, B. Wen, Hidden electronic rule in the "cluster-plus-glue-Atom" model, Sci. Rep. 6 (2016) 1-11, https://doi.org/ 10.1038 /srep33672.

[26] S. Xiang, Q. Li, M. Zuo, D. Cao, H. Li, Y. Sun, Influence of the preparation cooling rate on crystallization kinetics of Fe74Mo6P13C7 amorphous alloys, J. NonCryst. Solids 475 (2017) 116-120, https://doi.org/10.1016/ j.jnoncrysol.2017.09.012.

[27] D. Singh, R.K. Mandal, R.S. Tiwari, O.N. Srivastava, Effect of cooling rate on the crystallization and mechanical behaviour of $\mathrm{Zr}-\mathrm{Ga}-\mathrm{Cu}-\mathrm{Ni}$ metallic glass composition, J. Alloy. Comp. 648 (2015) 456-462, https://doi.org/10.1016/ j.jallcom.2015.06.275.

[28] D.V. Louzguine-Luzgin, Vitrification and devitrification processes in metallic glasses, J. Alloy. Comp. 586 (2014) 2-8, https://doi.org/10.1016/ j.jallcom.2012.09.057.

[29] Y. Wang, Y. Zhang, A. Takeuchi, A. Makino, Y. Kawazoe, Investigation on the crystallization mechanism difference between FINEMETi $i_{i}^{1 / 2}$ and NANOMETi $_{i}{ }^{1 / 2 t y p e}$ Fe-based soft magnetic amorphous alloys, J. Appl. Phys. 120 (2016), https://doi.org/10.1063/1.4964433, 0-6.

[30] T. Bitoh, A. Makino, A. Inoue, Origin of low coercivity of Fe-(Al, Ga)-(P, C, B, Si, Ge) bulk glassy alloys, Mater. Trans. 44 (2003) 2020-2024, https://doi.org/ 10.2320/matertrans.44.2020

[31] G. Herzer, Modern soft magnets: amorphous and nanocrystalline materials, Acta Mater. 61 (2013) 718-734, https://doi.org/10.1016/ j.actamat.2012.10.040.

[32] R.S. Turtelli, Quenched-in stresses in amorphous ribbons, J. Magn. Magn. Mater. 133 (1994) 20-23, https://doi.org/10.1016/0304-8853(94)90478-2.

[33] T. Kulik, M. Kopcewicz, Effect of quenching rate on magnetic properties and local magnetic anisotropy in Fe78Si9B13 glass, J. Magn. Magn. Mater. 215 (2000) 455-458, https://doi.org/10.1016/S0304-8853(00)00187-6.

[34] G. Herzer, Nanocrystalline soft magnetic materials, J. Magn. Magn. Mater. 157-158 (1996) 133-136, https://doi.org/10.1016/0304-8853(95)01126-9.

[35] S. Flohrer, R. Schäfer, G. Herzer, Magnetic microstructure of nanocrystalline FeCuNbSiB soft magnets, J. Non-Cryst. Solids 354 (2008) 5097-5100, https:// doi.org/10.1016/j.jnoncrysol.2008.07.034. 